\title{
WOOD PROCESSING BY-PRODUCTS TREATED WITH THE LIGNIN-BASED CONDITIONER AS MULCH FOR SOIL PROTECTION
}

\author{
Galia SHULGA ${ }^{a}$, Talrits BETKERS ${ }^{\mathrm{b}}$, Sanita VITOLINAc ${ }^{c}$, Brigita NEIBERTEd, Anrijs VEROVKINS ${ }^{\mathrm{e}}$, \\ Olga ANNE, Dalia AMBRAZAITIENE ${ }^{g}$, Audrone ZUKAUSKAITE ${ }^{\mathrm{h}}$ \\ ${ }_{a, c, d, e}$ Laboratory of Lignin Chemistry, Latvian State Institute of Wood Chemistry, \\ Dzerbenes iela 27, LV-1006 Riga, Latvia \\ ${ }^{b}$ Faculty of Building and Civil Engineering, Riga Technical University, \\ Azenes iela 16/20, LV-1048 Riga, Latvia \\ ${ }^{f}, g, h$ Faculty of Natural Sciences and Mathematics, Klaipeda University, \\ H. Manto g. 84, LT-5808 Klaipeda, Lithuania \\ ${ }^{h}$ Faculty of Marine Engineering, Klaipeda University, \\ Bijūnu g. 17, LT-91225 Klaipéda, Lithuania
}

Submitted 04 Jun. 2013; accepted 06 Feb. 2015

\begin{abstract}
Wood processing by-products such as bark of different wood species and hydrolysis lignin were applied as soil mulch. The lignin-based soil conditioner (LSC) representing a lignin-based polyelectrolyte complex with the different composition (a lignin/polymer mass ratio) was obtained under laboratory conditions and was intended to protect sandy soil from erosion by simultaneous application of a soil conditioner as an adhesive, mulch and plant seeds by hydroseeding. The study revealed the pronounced dependence of the properties of the treated wood-originated mulch on the wood species as well as on the composition, the applied concentration and the application rate of LSC. A comparison of the obtained results showed that the treated hydrolysis lignin was characterised by higher compressive strength, higher water resistance and lower moisture losses from sandy soil for a given LSC composition and application rate than the bark-based mulch. The conditioner concentrations don't have negative impact on the germination of seeds plants of the coastal dune zone.
\end{abstract}

Keywords: bark, hydrolysis lignin, lignin-based soil conditioner, mulch, soil erosion, seed germination.

\section{Introduction}

The peculiarities of the climatic conditions of the coastal zone of Latvia and Lithuania and non-coherent, structureless dune sand, on which the most popular species of conifers such as Pinus sylvestris, Picea excelsa and Pinus monticota grow, are the main reasons for riparian forest soil erosion. Unfortunately, methods of erosion control are labour intensive and sometimes are not very effective. To protect land by reducing soil erosion, afforestation and erection of hedges have been historically applied (Dymond et al. 2008; Shao et al. 2011).

The known management practice for mitigating soil erosion on non-agricultural land is based on the application of various mulching materials (Kim et al. 2008; Gimenez, Govers 2008; Foltz, Copeland 2009; Zhang et al. 2013). The application of fibre mulch for protection of erodable soil has been demonstrated for straw, wood chips, sawdust and synthetic products, including erosion control geonets, geotextiles, blankets and geomattings (Curnoe et al. 2006; Pack 2007; Calatrava, Franko 2011; Lee, Douglas 2012). Owing to the notable wood processing industry in the Baltic countries, a wide-scale wood waste such as sawdust and bark as well as hydrolysis lignin, a waste of the post-hydrolysis industry in Lithuania, in the form of organic mulch are economically available and promising erosion control products.

At the same time, the application of unanchored mulch may lead to its washout and blowing off and destroying of the soil mulched layers. An attractive solution to the erosion mitigation and control in the dune zone may be the biological reinforcement of the sandy soil surface

Corresponding author: Galia Shulga

E-mail: shulga@junik.lv 
by hydroseeding, combining simultaneous application of mulch, grass seeds, fertilisers and a soil polymer conditioner. A polymer conditioner attaches the mulch and grass seeds to the sandy surface, glues them by forming upper stabilised layers, and thereby prevents the washout and blowing off of mulch and reduces water runoff and soil loss (Sojka et al. 2007; Li et al. 2011).

The use of a natural polymer such as lignin is of great scientific and practical interest as a soil conditioner. Lignin is the world's second most abundant natural substance performing the function of polymeric glue in the wood matrix. Furthermore, lignin is a precursor of humus substances in soil. Commercial technical lignins are widescale and low-cost by-products of pulp and paper mills, and their application for the production of soil improving agents is well known (Dong et al. 2008; Shulga et al. 2008a; Aimi et al. 2009; Passauer et al. 2012). It has been found that the interaction of the lignin-based soil conditioners with the mineral surface of soil particles has a complicated character and is realised via various types of binding, including the Van der Waals forces of attraction as well as electrostatic and electron-donor-acceptor interactions (Kullmann 1982). The commercial lignin-based conditioners include the following: Sandstop, Dustex, Lima, Lia, Copolima, Copoliba, RoadBond, RP Ultra Plus ${ }^{\mathrm{TM}}$, BorrePlex CA, etc. In comparison to synthetic polymeric soil conditioners, the lignin-based conditioners biodecay in soil, increasing its fertility (Popa et al. 2010).

Various non-expensive lignin-based soil conditioners (LSCs) have been synthesised under laboratory conditions by the chemical modification of technical lignins, low-cost wide-scale by-products of pulp and paper mills, using various environmentally friendly polymeric or oligomeric modifiers, containing soil nutrient elements (Shulga et al. 2001). From the chemical point of view, the developed LSCs represent lignin-based polycomplexes, in which the macromolecules of lignin and the modifier are linked together with physicochemical bonds.

In the previous works (Shulga et al. 2007, 2008b), the developed lignin-based conditioner was applied for gluing mulch from wood sawdust and structuring sandy soil. It was found (Shulga et al. 2008b) that, after applying the water LSC solutions to the top of the soil mulched with wood sawdust, the layer soil-mulch composites were formed upon drying. They consisted of a thick upper glued layer $(20-50 \mathrm{~mm})$ of the sawdust and a thin lower glued layer $(1-3 \mathrm{~mm})$ of the soil.

It is quite important to emphasize, that lignin based conditioners and mulch are bind (fix) soil particles together and at the same time should be harmless for dune sand and for plants growing under the trees, especially for seeds germination. The sensitivity of Coastal zone "obligates" any technologies to be friendly for environment and don't have any negative impact to ecosystems. Only comprehensive research of proposed technology could contribute to successful results of its application.

The aim of this work was to study the comparison effect of the developed LSC on the properties of sandy soil-mulch composites obtained from wood-originated by-products, namely, wood bark and hydrolysis lignin.

\section{Objects and methods}

\subsection{Lignin-based soil conditioner}

Commercial lignosulphonate (LS), a by-product of softwood delignification, with an average molecular weight of $28 \mathrm{KDa}$ was used to obtain the new soil conditioner. The LS elementary and functional analysis gave the following formula: $\mathrm{C}_{9} \mathrm{H}_{6.89} \mathrm{O}_{2.57}\left(\mathrm{OCH}_{3}\right)_{0.71}\left(\mathrm{SO}_{3}\right)_{0.35}$ $(\mathrm{OHph})_{0.68}(\mathrm{CO})_{0.36}$. A lignin-based polyelectrolyte complex having different composition $\mathrm{Z}$ (from 0.02 to 1.00 ), which corresponded to the polymer/lignin mass ratio, was obtained via the chemical modification of LS with the acrylic polymer modifier according to the procedure (Shulga et al. 2007). It differed from the conditioners developed earlier by the enhanced colloidal stability at different $\mathrm{pH}$ values in water solutions.

\subsection{Soil}

Soil was taken from the coastal dune zone of the Curonian Spit of the Baltic Sea near Klaipeda (N-55, 67725, E-21, 10336, Lithuania). It was a very poor light sandy soil with the humus content below $0.1 \mathrm{wt} \%$ and a $\mathrm{pH}$ of 6.6. The sand was rich in phosphorus $(185 \mathrm{mg} / \mathrm{kg})$, but poor in potassium $(54 \mathrm{mg} / \mathrm{kg}$ ), which is typical for a dune sandy soil. The soil sample was obtained over a depth of $0-20 \mathrm{~cm}$ and had the following mechanical composition: $3.1 \%$ of particles ranging from 1.0 to $0.25 \mathrm{~mm}, 93.9 \%$ of particles ranging from 0.25 to $0.05 \mathrm{~mm}$, and $3.0 \%$ of particles less than $0.01 \mathrm{~mm}$ in size.

\subsection{Mulch}

The bark of the following wood species was used: aspen, birch, spruce and pine, which are readily available from Latvia's woodworking enterprises. Hydrolysis lignin was obtained from the manufacture of fodder yeast, the remaining wide-scale waste of the former Lithuanian hydrolysis industry.

The chemical composition of the applied bark (cellulose, lignin and extractives) is presented in Table 1. Before the study, the hydrolysis lignin was washed with hot distilled water for removing organic and mineral acid residues. The chemical composition of the hydrolysis lignin was the following: $\mathrm{pH} 5.1$; organic carbon $30.91 \mathrm{wt} \%$; total nitrogen 0.34 wt \%; $\mathrm{P}_{2} \mathrm{O}_{5} 404 \mathrm{mg} / \mathrm{kg} ; \mathrm{K}_{2} \mathrm{O}_{5} 831 \mathrm{mg} / \mathrm{kg}$; moisture content 7.1 wt $\%$. Besides lignin substances, this organic waste also contained non-hydrolysed polysaccharides 
$(25.8 \%)$ as well as small quantities of sugars $(1.3 \%)$ and cations of polyvalent metals $(5.47 \%)$.

Table 1. Chemical composition of bark

\begin{tabular}{|c|c|c|c|c|c|c|c|}
\hline \multirow{2}{*}{$\begin{array}{l}\text { Wood } \\
\text { species }\end{array}$} & \multirow{2}{*}{ 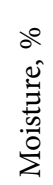 } & \multirow[b]{2}{*}{$\begin{array}{l}\text { a } \\
\frac{\hat{A}}{2}\end{array}$} & \multirow{2}{*}{$\overbrace{0}^{\circ}$} & \multirow{2}{*}{ 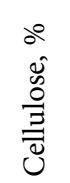 } & \multirow{2}{*}{ 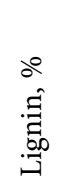 } & \multicolumn{2}{|c|}{$\begin{array}{c}\text { Extractives, \%, } \\
\text { soluble in }\end{array}$} \\
\hline & & & & & & $\begin{array}{l}\text { Hot } \\
\text { water }\end{array}$ & $\begin{array}{l}\text { Organic } \\
\text { mixture }^{\mathrm{x}}\end{array}$ \\
\hline Pine & 6.9 & 2.4 & 2.4 & 18.1 & 67.4 & 1.7 & 19.7 \\
\hline Spruce & 6.9 & 2.1 & 2.5 & 21.8 & 44.8 & 2.9 & 12.7 \\
\hline Birch & 6.3 & 4.3 & 5.1 & 25.2 & 40.0 & 9.5 & 3.9 \\
\hline Aspen & 5.9 & 4.2 & 3.6 & 22.1 & 26.6 & 9.6 & 8.0 \\
\hline
\end{tabular}

Note: ${ }^{\mathrm{x}}$ ethyl alcohol : benzene ratio is close to $1: 2$.

After mechanical grinding, fractions with the size ranging from 1 to $2 \mathrm{~mm}$ and less than $0.5 \mathrm{~mm}$ prevailed in the mechanical composition of the used mulches. Two layer thicknesses of mulch, namely, 2 and $5 \mathrm{~cm}$ were used to study the effect of the treated mulch on the soil chemical composition.

\subsection{Soil-mulch composites}

Because the composites formed after treating the mulched soil with a LSC solution were composed of an upper glued mulch layer and a lower glued soil one, it was expedient to investigate the effect of LSC on the properties of each layer separately.

\subsubsection{Glued soil layers}

For obtaining a glued soil surface layer, the set of the following procedures was carried out: (a) placing the slightly moistened sandy soil into aluminium containers $0.4 \mathrm{~m}$ square and $0.1 \mathrm{~m}$ in height; (b) treating the surface of the samples by spraying aqueous solutions of LSC with a defined concentration of 50-200 g/l at an application rate of $1.0-2.5 l / \mathrm{m}^{2}$; (c) drying the treated soil samples at room temperature.

The penetration resistance and thickness of the glued upper sandy layers were measured using a manual laboratory coner penetrometer (angle $30^{\circ}$ ) of original construction and a calliper square, described in detail earlier (Shulga et al. 2001). The wetting-drying test to investigate the water resistance of the formed glued layers was carried out according to the procedure (Shulga et al. 2001). Penetration resistance and thickness were measured at 8 locations on each coating, were averaged, and their standard deviation values were calculated.

To study the effect of climatic factors on the change in the penetration resistance of the glued surface soil layers, a climatic chamber Binder KBF LQC 240 (Binder, Germany) was used. The parameters of the test were chosen, taking into account the climatic conditions of the Baltic coastal zone - the high humidity and moderately high temperature of the soil upper layers at sunlight. The air-dried glued sandy samples were put into the climatic chamber having a temperature of $60{ }^{\circ} \mathrm{C}$, a humidity of $75 \%$ and the UV - radiation of $1.7 \mathrm{Wm}^{-2}$ (in the range of $320-400 \mathrm{~nm}$ ) and then exposed to the action of the climatic parameters during 5, 15 and 30 days. The number of replicates was three, and the presented results were average arithmetic values.

\subsubsection{Mulch-based composite materials and their properties}

To investigate the properties of the upper glued layer of mulch, the composite materials were made in accordance with the following set of procedures: (a) mixing the slightly moistened mulch with LSC water solutions with the defined concentration; (b) compacting the obtained raw mixtures in the form of cylinders $(2 \times 3 \mathrm{~cm})$ at a pressure of $0.1 \mathrm{MPa}$; (c) drying the cylinders at room temperature. The content of the mulch in the obtained composites was varied from $95 \mathrm{wt} \%$ to $75 \mathrm{wt} \%$ on the dry composite weight.

The ability of the conditioner to glue mulch particles was evaluated by the value of the destructive compressive strength of the obtained composite cylinders. For this purpose, the cylinders were placed between the platens of a universal testing machine (Instron, USA) and then compressed at a constant rate. Compressive strength was presented as an average value with a standard deviation for seven samples of each applied composition of LSC.

Water resistance of the obtained composites was evaluated visually by the time of the initiation of the disintegration of the cylinder fully immersed in cold distilled water $(287 \mathrm{~K})$. The time of the beginning of the sample decomposition in water was presented as an average value with a standard deviation measured for seven samples of each applied composition of LSC.

To study the effect of the mulch treated with a LSC solution on the moisture evaporation from sandy soil, procedures for preparing the samples were as follows: (a) covering the slightly moist sandy soil, placed in round plastic baths $0.12 \mathrm{~m}$ in height and a surface square of $0.016 \mathrm{~m}^{2}$, with a $2 \mathrm{~cm}$ layer of the slightly moist mulch; (b) treating the mulch surface with a water solution of LSC with a concentration of 50-200 g/l at an application rate of 2-6 $\mathrm{lm}^{-2}$; (c) drying the obtained soil samples to an air-dry state at room temperature. Then equal amounts of water were applied to the surface of each sample so that the total content of moisture in all samples would be equal and would make up 12.5-12.8 wt \%. The water evaporation from the soil surface was evaluated from the weight loss of the bath using the electron balance Kern 572 (Kern \& Sohn GmbH, 
Germany) with the readout $0.01 \mathrm{~g}$ upon its standing in the open air at the temperature $293 \pm 2 \mathrm{~K}$ and an air humidity of $60 \pm 2 \%$ every 12 hours. The soil sample was considered air-dried, if the weight of the bath stopped varying with increasing storage time in the given experimental conditions. The average weight loss with a standard deviation for seven samples with the same LSC application concentration and rate was calculated.

\subsection{Plants}

After evaluating a variety of coastal zone plants and dune flora, the following sorts of plants were chosen: Festuca rubra L., Gypsophila paniculata L., Thymus serpyllum L. These greeneries, according to their morphological and ecological properties, are most suitable for prevention of soil erosion in the dune zone of the Baltic Sea. The viability and germination energy of plant seeds were estimated at the Lithuanian State Seeds Laboratory in accordance with international research methods (International Seed Testing Association 1996). Viability and germination energy of the seeds were analysed on Petri plates in five replicates, using distilled water and nutrient solutions wetting the filter paper. Dishes with the seeds were incubated in a biological incubator using: an incubation temperature of $20{ }^{\circ} \mathrm{C}$ for Gypsophila paniculata L., evaluation of seeds viability after 4,10 and 14 days; an incubation temperature

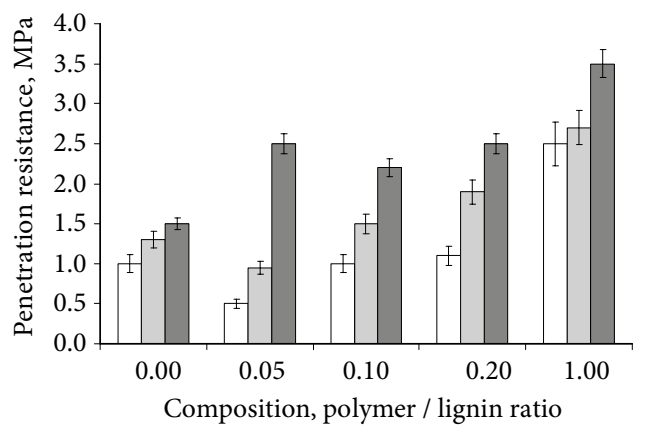

Fig. 1. Penetration resistance of reinforced soil layers versus the LSC composition; concentration of the applied solutions: $\square, 50 \mathrm{~g} / \mathrm{l} ; \quad, 100 \mathrm{~g} / \mathrm{l} ; \square, 200 \mathrm{~g} / \mathrm{l}$; application rate $1.5 \mathrm{l} / \mathrm{m}^{2}$

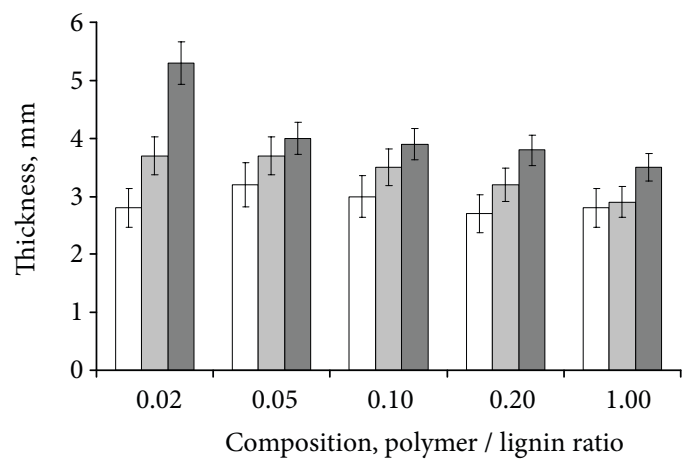

Fig. 2. Thickness of reinforced soil layers versus the LSC composition; concentration of the applied solutions: $\square 50 \mathrm{~g} / \mathrm{l}$; $100 \mathrm{~g} / \mathrm{l} ; \quad 200 \mathrm{~g} / \mathrm{l}$; application rate $1.5 \mathrm{l} / \mathrm{m}^{2}$ of $20-30^{\circ} \mathrm{C}$ for Thymus serpyllum L. and Festuca rubra L., evaluation of seeds viability after 7 and 21 days. Germinated, non-germinated and abnormal seeds were counted every time. Statistical analysis was made using Statgraphics plus software $\pm \mathrm{x}-$ mean square deviation. The significance levels of the results are given for seed germination characteristics (ANOVA): $\mathrm{S}_{\mathrm{x} \%}$ - standard deviation; $\mathrm{LSD}_{05}$ - least significant difference.

\section{Results and discussion}

\subsection{Effect of the lignin-based soil conditioner on the properties of sandy soil layers}

According to our findings, the penetration resistance and thickness of the glued sandy layers formed depend on the concentration of the applied water solutions and the application rate, as well as on the LSC composition. The penetration resistance and thickness of the glued upper soil layers increase from 0.05 to $3.50 \mathrm{MPa}$ and from 0.5 to $6.1 \mathrm{~mm}$, respectively, with increasing application rate of the LSC solutions from 1.0 to $2.5 \mathrm{l} / \mathrm{m}^{2}$, the concentration from 10 to $200 \mathrm{~g} / \mathrm{l}$ and $\mathrm{Z}$ from 0.02 to 0.2 . Figures 1 and 2 demonstrate the dependences of the penetration strength and thickness of the glued soil layers for the different concentrations of the applied solutions on the LSC composition, at an application rate of $1.5 \mathrm{l} / \mathrm{m}^{2}$. Reasoning from the obtained data and taking into account the results of our previous work (Shulga et al. 2001), this application rate has to be sufficient to impart the optimum value of mechanical strength and thickness to the sandy layer. With increasing the composition of the LSC from 0.05 to 1.00 and its concentration in a water solution from $50 \mathrm{~g} / \mathrm{l}$ to $200 \mathrm{~g} / \mathrm{l}$ at the same application rate, the penetration strength of the layers increases 1.8-2.5 times.

The observed gain in the mechanical properties may be governed by increasing the LSC flocculation ability relative to the soil particles as a result of the enhancement in the molecular weight of the lignin/polymer complex, which was testified by an increase in the maximum dynamic viscosity of the LSC solutions with an increase in $\mathrm{Z}$ (Shulga et al. 2008b). At the same time, the thickness of the glued sandy layers decreases with the growth in the composition $(Z \geq 0.1)$ and concentration $(>100 \mathrm{~g} / l)$ of the LSC solutions (Fig. 2) that may be caused by their lower infiltration into the soil due to the growth of dynamic viscosity. The higher values of thickness for the glued soil layers are provided by the application of the solutions of the LSC with $Z=0.02-0.05$, having lower values of dynamic viscosity.

It was found that the changes in the penetration resistance of the glued soil layers during a test on wetting/ drying cycles depended non-linearly on the LSC composition. The sandy layers treated with the solutions of the LSC with $0.1 \leq Z \leq 0.2$ and the concentration $50-200 \mathrm{~g} / l$ had 
the highest resistance to the action of the wetting/drying cycles. Obviously, the ability of the glued soil layers to resist the destructive action of the wetting/drying cycle is defined by the cohesion strength of the LSC polymer network formed, which is directly connected with the reduced viscosity of the lignin/polymer solutions. The obtained correlations are similar to those that have been earlier found for the water resistance of the artificial sandy aggregates (Shulga et al. 2008b).

It is known that the combined prolonged effect of climatic factors such as temperature, humidity and solar radiation could have a negative action on the gluing properties of a polymer conditioner due to irreversible chemical transformations in its structure, which can be governed by both the hydrolysis of its chemical bonds owing to the presence of elevated humidity and destruction reactions as a result of the integrated action of elevated temperature and UV-radiation. The revealed changes in the properties of the glued soil layers after their exposure in a climatic chamber allows evaluating weather resistance of the developed soil conditioner itself. Table 2 shows the values of the penetration resistance of the glued soil layers subjected to the simultaneous action of the elevated temperature, the humidity and the UV-radiation in different periods of time. It can be seen that, with increasing the exposure time, the penetration resistance of the glued soil layers decreases. The values of the decrease in the penetration resistance depend on the composition of LSC.

After 30 days of the exposure in the chamber, the decrease in the penetration resistance for the lowest LSC composition $Z=0.02$ is equal to $26 \%$, but, with increasing $\mathrm{Z}$ to $0.1-0.2$, the changes of the resistance decrease and vary in the range of $12-17 \%$. Taking into account the moderate changes of the mechanical strength of the glued soil layers, it may be concluded that the weather resistance of the developed LSC is sufficient for retaining its binding properties during the period of plant development and the formation of turf on mulched soil.

\subsection{Effect of the lignin-based soil conditioner composition on the properties of mulch-based composites}

The binding properties of the soil conditioner relatively to the mulch were investigated using several series of the composite cylinders, in which bark and hydrolysis lignin were used as a filler and LSC was applied as a binder. It was found that, with growing content of LSC with Z = $0.02-0.2$ from 5 to $25 \mathrm{wt} \%$ in the composites, their compressive strength increased 2.5-4.5 times, while the density of the bark- and hydrolysis lignin-based composites increased from 521 to $598 \mathrm{~kg} / \mathrm{m}^{3}$ and from 557 to $612 \mathrm{~kg} / \mathrm{m}^{3}$, respectively. The effect of the LSC composition on the compressive strength of the composites from the bark of the different wood species and the hydrolysis lignin at the
Table 2. Penetration resistance of air-dried glued sandy soil layers $^{\mathrm{xx}}$ after exposure in the climatic chamber "Binder" during different time

\begin{tabular}{ccccc}
\hline \multirow{2}{*}{$\begin{array}{c}\text { Compo- } \\
\text { sition, } Z\end{array}$} & \multicolumn{4}{c}{ Penetration resistance, MPa/Time, days } \\
\cline { 2 - 5 } & 0 & 5 & 15 & 30 \\
\hline 0.02 & $1.30 \pm 0.12$ & $1.23 \pm 0.14$ & $1.09 \pm 0.13$ & $0.96 \pm 0.16$ \\
0.1 & $1.51 \pm 0.17$ & $1.48 \pm 0.18$ & $1.39 \pm 0.14$ & $1.26 \pm 0.19$ \\
0.2 & $1.92 \pm 0.21$ & $1.90 \pm 0.20$ & $1.82 \pm 0.22$ & $1.70 \pm 0.24$ \\
\hline
\end{tabular}

Note: ${ }^{\mathrm{xx}}$ concentration of LSC solutions - $100 \mathrm{~g} / \mathrm{l}$; application $-1.51 \mathrm{~m}^{2}$.

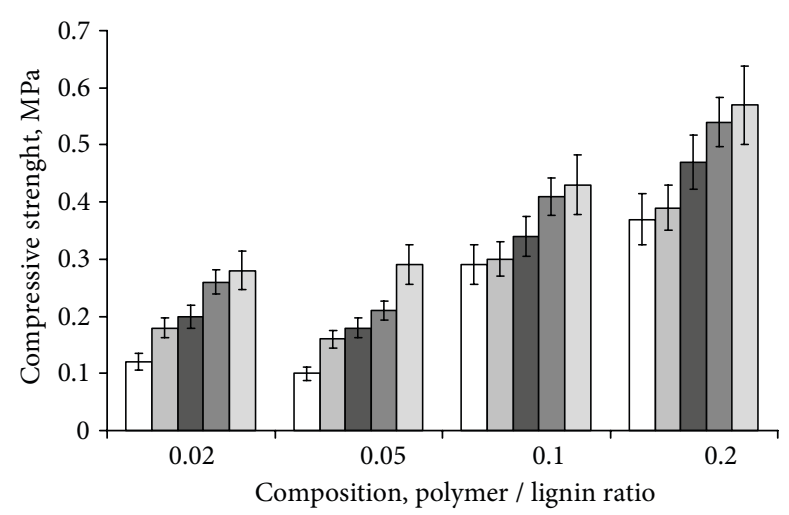

Fig. 3. Compressive strength of composites made from $\square$ pine bark; $\square$, spruce bark; $\square$, birch bark; $\square$, aspen bark; $\square$, hydrolysis lignin; LCS content $25 \mathrm{wt} \%$ on the dry matter of the composite

maximum content of the soil conditioner is demonstrated in Figure 3. Evidently, the presence of active reaction centres in the hydrolysis lignin in the form of polyvalent metal ions increases its specific surface, which, together with the high-developed porous structure, reinforces the adhesion interaction at the LSC/filler interface.

It can be seen (Fig. 3) that the compressive strength of the obtained composites increases with growing the $\mathrm{Z}$ values and reaches a maximum at $Z=0.2$. The mulchbased composites obtained with $Z=0.02-0.05$ are characterised by weak mechanical properties. The increase in the composition of LSC from 0.05 to 0.2 results in a 1.5-3.8-fold growth in compressive strength, depending on the type of the wood filler. It should be noted that the composites filled with the bark of deciduous wood species have higher values of compressive strength than those filled with the bark of coniferous species. The found dependence of the gluing ability of LSC on the wood species of bark may be governed by the peculiarities of the chemical composition of bark of deciduous and coniferous wood species, which is confirmed by the data of extraction with an alcohol-benzene mixture of the latter (Table 1). A considerable amount of resin, extracted from the bark of conifers in the organic mixture, can weaken the adhesive interaction between the soil conditioner and the surface of the bark particles. At the same time, the hydrolysis lignin-based composites are characterised by the highest compressive strength for a given $\mathrm{Z}$ (Fig. 3). Taking into 
account these results, it may be supposed that the deformation of the obtained mulch-based composites subjected to the shear forces of wind and water flow during their field application will not be dramatic.

With increasing the content of LSC from $5 \mathrm{wt} \%$ to $25 \mathrm{wt} \%$ in the range of $\mathrm{Z}=0.02-0.2$, the time of the onset of the disintegration of the composite cylinders immersed in cold water increases 5-15 times, depending on the kind of the wood filler. Figure 4 shows the values of time for the composites filled with the bark of the different wood species and the hydrolysis lignin, depending on the composition of LSC at its content $25 \mathrm{wt} \%$. According to the obtained results, the composites filled with the bark of deciduous wood species are characterised by a higher resistance to destruction under the action of water than the composites based on the bark of coniferous wood species. It can be seen that, in the range of $\mathrm{Z}=$ $0.02-0.05$, the water resistance of the obtained composites is low and practically does not depend on the LSC composition. With increasing $\mathrm{Z}$ from 0.05 to 0.20 , the time of the onset of disintegration for the composites

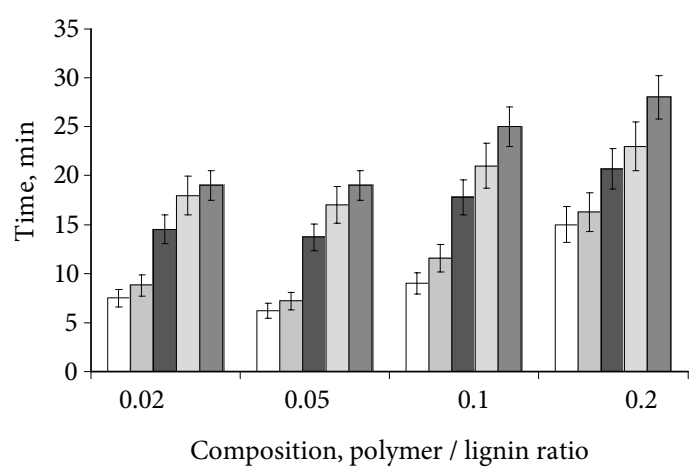

Fig. 4. Time of the onset of disintegration in cold water for composites made from $\square$, pine bark; $\square$, spruce bark; $\square$, birch bark; , , aspen bark; $\square$, hydrolysis lignin; LCS content 25 wt $\%$ on the dry matter of the composite

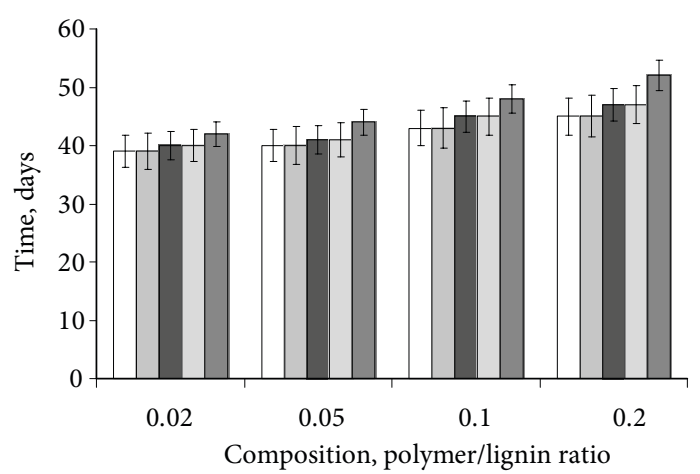

Fig. 5. Effect of moisture evaporation for sandy soil mulched with composite materials formed from $\square$, pine bark; $\square$, spruce bark; $\square$, birch bark; $\square$, aspen bark (4), $\square$, hydrolysis lignin (5) on the composition of LSC; concentration of the solutions $100 \mathrm{~g} / \mathrm{l}$, the application rate $4.0 \mathrm{l} / \mathrm{m}^{2}$ made from the bark of coniferous wood species grows twice, while, for the composites filled with the bark of deciduous wood and the hydrolysis lignin, the time increases only 1.3-1.5 times.

At the same time, the more pronounced water resistance of the hydrolysis lignin-based composite (Fig. 4) may be connected with the more developed system of the interfacial physico-chemical bonds between LSC and the filler, which has a favourable effect on the hydrophobicity of the composite materials.

\subsection{Effect of mulch-based composites on the evaporation of soil moisture}

The results of the performed tests have shown that the uncovered soil sample dry out in 22 days, while the samples covered with the bark and the hydrolysis lignin not glued with the soil conditioner dry out in 33 and 34 days, respectively. The ability to retain more soil moisture for hydrolysis lignin in comparison with the case of bark as mulch may be governed by its developed specific surface. The soil samples treated with the LSC solution dry out in 39-52 days, depending on the composition of the soil conditioner, the concentration of its solution, the application rate as well as the type of mulch. These data exceed by $77-163 \%$ and $18-57 \%$ the drying time of the uncovered soil and the untreated mulch samples, respectively. With higher $\mathrm{Z}$ values, at the same LSC concentration and application rate, the mulching effect tends to grow (Fig. 5). Higher LSC composition results in longer drying periods. This tendency manifests itself most dramatically in $\mathrm{Z}$ values in the range of $0.05-0.2$. The lowest rate of the moisture evaporation is achieved with the deciduous wood bark and the hydrolysis lignin treated with the LSC solutions having $\mathrm{Z}=0.1-0.2$ and a concentration of $100-150 \mathrm{~g} / \mathrm{l}$.

It has been found that the effect of the studied concentration of the applied solutions and the application rate in the range $2-6 \mathrm{l} / \mathrm{m}^{2}$ on the moisture losses from the mulched soil samples has a more complicated character. At the solution concentration $>100 \mathrm{~g} / \mathrm{l}$ and the consumption $2 \mathrm{l} / \mathrm{m}^{2}$, the soil conditioner, passing through the mulch, is mainly adsorbed on its particles, gluing them together in the air-dry sate. In this case, the adherence of the mulch to the soil as well as the mechanical strength of the upper soil layers is relatively low due to the shortage of the LSC solution. An increase in the application rate of the conditioner solutions up to $4 \mathrm{l} / \mathrm{m}^{2}$ in the same concentration range enhances the adhesion interaction at the mulch/soil interface and forms a glued soil layer under the mulch. In this case, the degree of binding the mulch practically does not change. At the application rate of the solution $6 \mathrm{l} / \mathrm{m}^{2}$, the excess of the LSC solution, concentrating mainly at the mulch/soil interface, enhances significantly the penetration resistance of the glued soil layers. However, owing to 
the features of the LSC polymer structure and the porous surface of the formed glued sandy soil layers, no considerable decrease in the moisture evaporation from the mulched soil has been achieved. On the other hand, the decrease in the concentration of the solutions of LSC $<100 \mathrm{~g} / \mathrm{l}$ within the application rates under this study results in the worsening of gluing both the mulch and the soil particles, which leads to a faster evaporation of moisture from the mulched soil. A comparative analysis of the obtained results suggests that the application of $100-150 \mathrm{~g} / \mathrm{l}$ solutions of LSC with $\mathrm{Z}=0.1-0.2$ at the rate of $4 \mathrm{l} / \mathrm{m}^{2}$ may be the optimum one for treating a $2 \mathrm{~cm}$ mulched layer with the aim to diminish the evaporation of moisture from sandy soil.

\subsection{Effect of the lignin-based soil conditioner composition on seeds' viability and germination}

To assess the effect of the developed soil conditioner on the seeds' viability and germination energy, the water solutions of LSC, having $Z=0.02,0.1$ and 0.2 , were used. The conducted study has shown that the composition and concentration of LSC in the solution are crucial factors, which influence variously the Gypsophila paniculata, Thymus serpyllum and Festuca rubra seeds' germination and viability. According to Figure 6 (a, b, c), the $10-100 \mathrm{~g} / \mathrm{l}$ and $10-50 \mathrm{~g} / \mathrm{l} \mathrm{LSC}$ solutions, irrespective of the $\mathrm{Z}$ values, have a favourable action on the viability and germination energy of all the plant seeds.

At these LSC solution concentrations, the germinative energy for Gypsophila paniculata L. seeds after 4 days and for Thymus serpyllum and Festuca rubra seeds after 7 days is increased compared to the case of the control.

After 14 and 21 days, the quantity of normally developed seeds for Gypsophila paniculata as well as Thymus serpyllum and Festuca rubra, respectively, on the average, is equal to the control.

For the higher concentrations $(>100 \mathrm{~g} / l)$ of LSC with $\mathrm{Z} \geq 0.2$, the seed germinative energy and viability drop. According to Figure 6 (b, c), the effect on the seeds' germination for Thymus serpyllum and Festuca rubra is dramatic. The LSC solutions with $Z=0.02$ and $Z=0.1$ are more favourable for the seed germination of these kinds of plants. It should be noted that the high concentrations of LSC are not harmful to all the plants, since most parts of the non-germinated seeds remain undamaged and survive in the Petri dishes. Using an optical microscope, we have found that the high LSC concentrations, characterised by high values of dynamic viscosity, form thick polymeric films at the seeds' surfaces, which can hinder the access of water to plant seeds. It is known that, during the germination period, seeds should get $35-60 \%$ of the total water quantity needed, and water shortage dramatically reduces the seed germination.
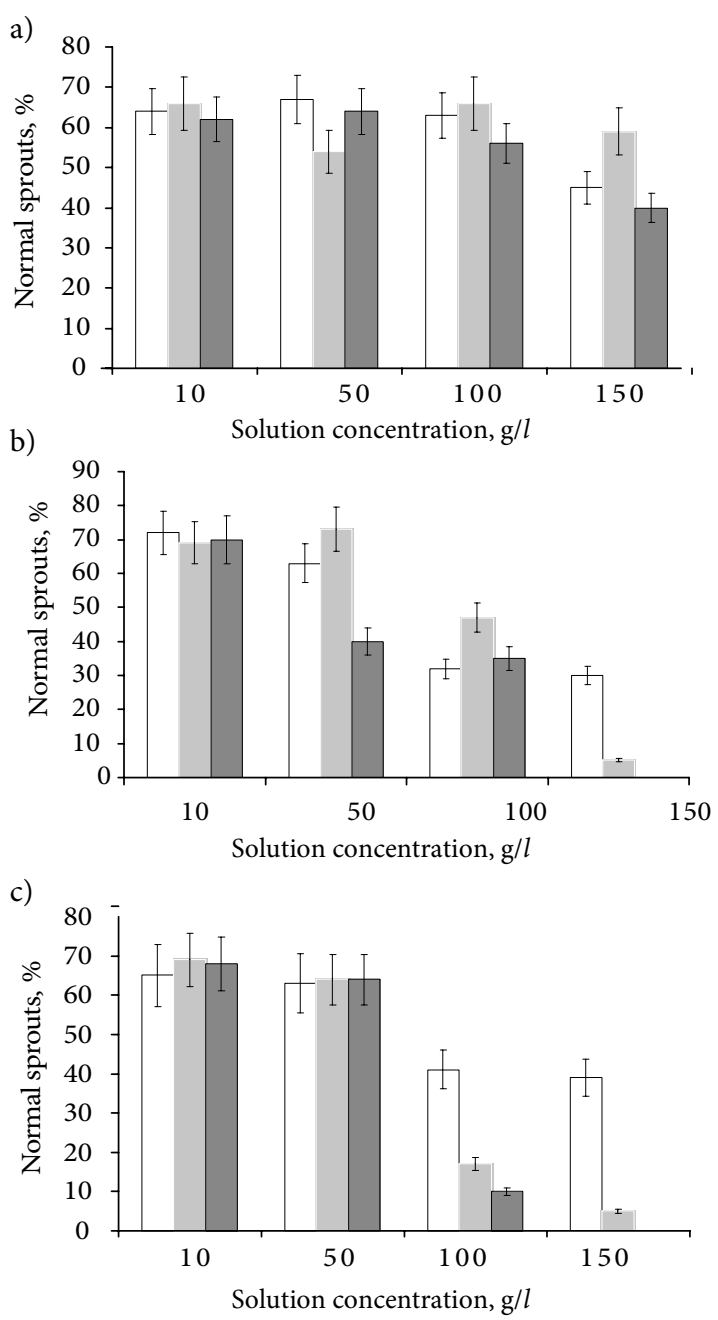

Fig. 6. Seed germination of Gipsophila paniculata L. (a) on 14th day after the onset of the experiment $\left(\operatorname{LSD}_{05} 6.10, \mathrm{~S}_{\mathrm{X} \%}=4.04\right)$; Thymus serpyllum L. $\left(\mathrm{LSD}_{05}=6.51, \mathrm{~S}_{\mathrm{X} \%}=2.29\right)(\mathrm{b})$ and Festuca rubra L. $\left(\mathrm{LSD}_{05}=4.98, \mathrm{~S}_{\mathrm{X} \%}=5.01\right)$ (c) on 21 st day after the onset of the experiment versus the concentration of the applied solutions of LSC with different composition: $\square, 0.02$; $\square, 0.10$; , 0.20

\section{Conclusions}

1. Due to a pronounced gluing ability, the developed lignin-based conditioner is capable of reinforcing the surface layers of sandy soil with a thickness of $0.5-6.1 \mathrm{~mm}$ and a penetration resistance of $0.5-3.5 \mathrm{MPa}$ with increasing an application rate of its water solution from 1.0 to $2.5 \mathrm{l} / \mathrm{m}^{-2}$ and a solution concentration from 10 to $200 \mathrm{~g} / \mathrm{l}$.

2. The two layered soil-mulch composite coverings, formed after applying the water conditioner solution to the top of the sandy soil mulched with the wood processing by-products, more efficiently suppressed the moisture evaporation from the soil in comparison with the untreated mulch covering. Evidently, the developed system of the interfacial physico-chemical bonds between the conditioner and the mulch has a favourable effect on the hydrophobicity of the formed soil-mulch composite. The 
gluing efficiency of the soil conditioner towards the mulch depends on its composition, the applied solution concentration and the application rate.

3. Owing to the presence of a considerable amount of resin substances in the bark of conifers that can weaken the adhesive interaction between the conditioner and the mulch particles, the composite covering from the conifer wood bark has worse mulching properties than the mulch covering from the bark of deciduous wood.

4. The treated hydrolysis lignin-based mulch was characterised by higher compressive strength, higher water resistance and lower moisture losses from sandy soil for a given conditioner composition and application rate than the treated bark-based mulch due to the enhanced specific surface of the hydrolysis lignin as well as its highdeveloped porous structure, promoting the adhesion interaction between the conditioner and the mulch.

5. The $10-100 \mathrm{~g} / \mathrm{l}$ LSC solutions, irrespective of the conditioner composition, have a favourable action on the viability and germination energy of the plant seeds from typical plants of the coastal dune zone. More concentrated solutions of LSC form the thick polymeric films at the seeds' surfaces, which can hinder the access of water to plant seeds.

\section{Acknowledgements}

The authors are grateful to the Latvian and Lithuanian Councils of Science for the financial support of the Eureka project E!2622 "Prevention and Control of Forest Soil Erosion on the Coastal Strip of the Baltic Sea by Using the Lignin-Based Polymers".

\section{References}

Aimi, H.; Ohmura, S.; Uetake, M.; Shimizu, K. 2009. Development of acid soil conditioning agent from lignin by ozone treatment II, Journal of Wood Science 55: 121-125. http://dx.doi.org/10.1007/s10086-008-1010-4

Calatrava, J.; Franco, J. A. 2011. Using pruning residues as mulch: analysis of its adoption and process of diffusion in Southern Spain olive orchards, Journal of Environmental Management 92: 620-629.

http://dx.doi.org/10.1016/j.jenvman.2010.09.023

Curnoe, W. E.; Irving, D. C.; Dow, C. B.; Velema, G.; Unc, A. 2006. Effect of spring application of a paper mill soil conditioner on corn yield, Agronomy Journal 98: 423-429. http://dx.doi.org/10.2134/agronj2005.0041

Dymond, J. R.; Ausseil, A. G. E.; Overton, J. M. 2008. A landscape approach for estimating the conservation value of sites and site-based projects, with examples from New Zealand, Ecological Economics 66: 275-281. http://dx.doi.org/10.1016/j.ecolecon.2008.03.008

Dong, Z.; Wang, L.; Zhao, S. 2008. A potential compound for sand fixation synthesized from the effluent of pulp and paper mills, Journal of Arid Environments 72: 1388-1393. http://dx.doi.org/10.1016/j.jaridenv.2008.02.008
Foltz, R. B.; Copeland, N. S. 2009. Evaluating the efficacy of wood shreds for mitigating erosion, Journal of Environmental Management 90: 779-785.

http://dx.doi.org/10.1016/j.jenvman.2008.01.006

Gimenez, R.; Govers, G. 2008. Effects of freshly incorporated straw residue on rill erosion and hydraulics, Cattena 72 : 214-223. http://dx.doi.org/10.1016/j.catena.2007.05.004

International Seed Testing Association. 1996. International Rules for Seed Testing. International Society for Horticultural Science.

Kim, C.-G.; Kwangil, S.; Joo, K. J.; Lee, K. S.; Shin, S. S.; Yeonsook, C. 2008. Effects of soil conservation measures in a partially vegetated area after forest fires, Science of the Total Environment 399: 158-164.

http://dx.doi.org/10.1016/j.scitotenv.2008.03.034

Kullmann, A. 1982. Synthetic soil conditioners. Moscow: Kolos, 84-86 (in Russian).

Lee, E. C.; Douglas, R. S. 2012. Geotextile tubes as submerged dykes for shoreline management in Malaysia, Geotextiles and Geomembranes 30: 8-15.

http://dx.doi.org/10.1016/j.geotexmem.2011.01.003

Li, Y.; Shao, M.; Horton, R. 2011. Effect of polyacrylamide applications on soil hydraulic characteristics and sediment yield of sloping land, Procedia Environmental Sciences 11(B): 63-73. http://dx.doi.org/10.1016/j.proenv.2011.12.118

Pack, J. 2007. Hydromulch passes test for steep slope stabilization with the North Carolina DOT, Land and Water 51: 15-17.

Passauer, L.; Struch, M.; Schuldt, S.; Appelt, J.; Schneider, Y.; Jaros, D.; Rohm, H. 2012. Dynamic moisture sorption characteristics of xerogels from water-swellable oligo (oxyethylene) lignin derivatives, ACS Applied Materials \& Interfaces 4: 5852-5862. http://dx.doi.org/10.1021/am3015179

Popa, V . I.; Stingu, A. P.; Volf, I. 2010. Lignin and Polyphenols in Bioremediation, in Bioremediation Technology: Recent Advances, M. H. Fulekar (Ed.). Capital Publishing Company, Springler, Heidelberg. http://dx.doi.org/10.1007/978-90-481-3678-0_4

Shao, G.; Dai, L.; Dukes, J. S.; Jackson, R. B.; Tang, L.; Zhao, J. 2011. Increasing forest carbon sequestration through cooperation and shared strategies between China and the United States, Environmental Science Technology 45: 2033-2034. http://dx.doi.org/10.1021/es200147k

Shulga, G.; Rekners, F.; Varslavans, J. 2001. Lignin-based interpolymer complexes as a novel adhesive for protection against erosion of sandy soil, Journal of Agricultural Engineering Research 78: 309-316. http://dx.doi.org/10.1006/jaer.2000.0599

Shulga, G.; Betkers, T.; Shakels, V.; Neiberte, B.; Verovkins, A.; Brovkina, J.; Belous, O.; Ambrazaitene, D.; Žukauskaite, A. 2007. Effect of the modification of lignocellulosic materials with a lignin-polymer complex on their mulching properties, BioResources 2: 572-582.

Shulga, G.; Betkers, T.; Brovkina, J.; Neiberte, B.; Verovkins, A.; Belous, O.; Ambrazaitene, D.; Žukauskaite, A. 2008a. New lignin-based polymers for ecological rehabilitation, Molecular Crystals and Liquid Crystals 483: 1333-1347.

Shulga, G.; Betkers, T.; Brovkina, J.; Aniskevicha, O.; Ozolinš, J. 2008b. Relationship between composition of the lignin-based interpolymer complex and its structuring ability, Environmental Engineering and Management Journal 7(4): 397-400.

Sojka, R. E.; Bjorneberg, D. L.; Entry, J. A.; Lentz, R. D.; Orts, W. J. 2007. Polyacrylamide in agriculture and environmental land 
management, Advances in Agronomy 92: 75-162. http://dx.doi.org/10.1016/S0065-2113(04)92002-0

Zhang, G.; Zhang, X.; Hu, X. 2013. Runoff and soil erosion as affected by plastic mulch patterns in vegetable field at Dianchi lake's catchment, China, Agricultural Water Management 122: 20-27. http://dx.doi.org/10.1016/j.agwat.2013.02.004

Galia SHULGA. Doctor of Polymer Chemistry (1982); Doctor Habilitatus of Wood Chemistry (1998). Leading researcher, Department of Lignin Chemistry, Latvian State Institute of Wood Chemistry (LSIWC). Publications: author/co-author over 200 scientific papers, 17 patents. Research interests: wood chemistry and technology, soil melioration, environmental technologies.

Talrits BETKERS. Master of Engineering Sciences (2007). Researcher, Faculty of Building and Civil Engineering, Riga Technical University (RTU). Publications: author/co-author over 50 scientific papers. Research interests: engineering sciences, environmental technologies.

Sanita VITOLINA. Master of Chemistry (2011). Researcher, Department of Lignin Chemistry, Latvian State Institute of Wood Chemistry (LSIWC). Publications: author/co-author over 30 scientific papers. Research interests: lignin chemistry and modification, environmental technologies.

Brigita NEIBERTE. Master of Chemistry (2006). Researcher, Department of Lignin Chemistry, Latvian State Institute of Wood Chemistry (LSIWC). Publications: author/co-author over 90 scientific papers, 3 patents. Research interests: lignin and lignocellulosic material modification, analytical chemistry of lignin, wood products.

Anrijs VEROVKINS. Master of Chemistry (2007); Doctor of Wood Chemistry (2013). Researcher, Department of Lignin Chemistry, Latvian State Institute of Wood Chemistry (LSIWC). Publications: author/co-author over 40 scientific papers. Research interests: lignin and bark modification, wood products, engineering sciences.

Olga ANNE. Doctor of Technological Sciences (1993). Professor of Ecology Department of Klaipeda University. Main areas of activity: Environmental Management, Environmental Impact Assessment, Renewable Energy. Publications: author/co-author over 50 scientific papers.

Dalia AMBRAZAITIENE. Doctor of Natural Sciences (1987), HP in Biomedical sciences; Professor of Ecology Department of Klaipeda University. Research interests: technological and environmental aspects related to use of nitrogen fixing bacteria preparations, biodegradation of organic materials and oil products in the soil, estimation of soil microbiological properties.

Audrone ZUKAUSKAITE. Doctor of Natural Sciences (1993). Assoc. Prof. Dr, Department of Technological Processes, Klaipeda University. Publications: author of more than 50 research papers. Research interests: waste treatment technologies, biodegradation of oil products. 